Binghamton University

The Open Repository @ Binghamton (The ORB)

\title{
The Anthropocentric Advantage? Environmental Ethics and Climate Change Policy
}

Nicole Hassoun

Binghamton University--SUNY, nhassoun@binghamton.edu

Follow this and additional works at: https://orb.binghamton.edu/philosophy_fac

Part of the Philosophy Commons

\section{Recommended Citation}

Hassoun, Nicole, "The Anthropocentric Advantage? Environmental Ethics and Climate Change Policy" (2011). Philosophy Faculty Scholarship. 4.

https://orb.binghamton.edu/philosophy_fac/4

This Article is brought to you for free and open access by the Philosophy at The Open Repository @ Binghamton (The ORB). It has been accepted for inclusion in Philosophy Faculty Scholarship by an authorized administrator of The Open Repository @ Binghamton (The ORB). For more information, please contact ORB@binghamton.edu. 


\title{
The Anthropocentric Advantage?
}

\author{
Environmental Ethics and Climate Change Policy
}

\section{Nicole Hassoun ${ }^{\mathrm{i}}$}

\begin{abstract}
:
Environmental ethicists often criticize liberalism. For, many liberals embrace anthropocentric theories on which only humans have non-instrumental value. Environmental ethicists argue that such liberals fail to account for many things that matter or provide an ethic sufficient for addressing climate change. These critics suggest that many parts of nature -- non-human individuals, other species, ecosystems and the biosphere have a kind of value beyond what they contribute to human freedom (or other things of value). This article suggests, however, that if environmental ethics are inclusive and also entail that concern for some parts of nature does not always trump concern for others, they have a different problem. For, when there are many things of value, figuring out what to do can be extremely difficult. Even though climate change is likely to cause problems for many parts of nature it will probably be good for some other parts. Inclusive environmental ethicists need a theory taking all of the things they care about into account to provide definitive reason even to address climate change. Without this theory, anthropocentric liberals might argue that we should not accept an inclusive environmental ethic. Although there may be something wrong with this line of thought, it at least raises a puzzle for those inclined to accept these ethics.
\end{abstract}

Key Words:

Climate Change, Liberalism, Environmental Ethics, Anthrpocentrism, Nature, Value, Pluralism

\section{Introduction}

Liberalism is defined by a commitment to some kind of human freedom. There are many ways of understanding this commitment. Some theories start from a concern for each individual's positive freedoms or capabilities (Nussbaum 2007, 23-24). On others, negative freedoms (e.g. from arbitrary interference) are of primary importance (Lomasky 1987, ch. 5; Machan 2001; Nozick 1974). Most liberal theories balance a concern for 
different kinds of freedom against other things of value (Rawls 1971; Raz 1998). On most ways of understanding the commitment to human freedom at the heart of liberalism, however, it provides definitive reason to mitigate climate change. For, anthropogenic climate change threatens to undermine individuals' basic capabilities and interfere with their negative freedoms. It threatens some individuals' ability even to survive (Hassoun 2009a; Jamieson 2005).

Nevertheless, environmental ethicists often criticize liberalism. At least they criticize anthropocentric versions of liberalism on which only humans have noninstrumental value. ${ }^{\text {ii }}$ Environmental ethicists argue that such ethics fail to account for many things that matter and are not sufficient for addressing climate change. ${ }^{\mathrm{ii}}$ These critics suggest that many parts of nature -- non-human individuals, other species, ecosystems and the biosphere -- have a kind of value beyond what they contribute to human freedom (or other things of value). ${ }^{\text {iv }}$ At least inclusive environmental ethicists, who believe concern for some parts of nature does not always trump concern for others, can object in this way to the anthropocentric liberals' arguments. There is probably something to inclusive environmental ethics as well as the above critique of anthropocentric liberalism.

Nevertheless, this article suggests that, when it comes to providing definitive reason to accept climate change policies, the problem might be on the side of inclusive environmental ethics. For, when there are many things of value, figuring out what to do can be extremely difficult. Even though climate change is likely to cause problems for many parts of nature it will probably be good for some other parts. Inclusive environmental ethicists need a theory taking all of the things they care about into account 
to provide definitive reason even to address climate change. Without this theory, anthropocentric liberals might argue that we should not accept an inclusive environmental ethic.

Next, this article provides a tentative response to this last strand of argument. Although inclusive environmental ethicists cannot offer definitive reason to accept their preferred climate change policies, their theories might be developed further in order to provide this justification. Some such ethics even be developed enough right now that they will allow us to make all of the necessary choices on the ground when we need to make them. Moreover, this article argues, there is reason to be optimistic about the prospects for some inclusive environmental ethics to address climate change.

Finally, the article suggests that whether or not everyone would accept its argument, it may be of interest even to those who reject inclusive environmental ethics. For many theories endorse more than one kind of value and lack principles for resolving all of the conflicts that may arise between these values. Indeed some anthropocentric liberal theories are also like this. So this article's lessons may be important even for some liberals.

Section 2 considers an argument anthropocentric liberals might give against inclusive environmental ethics. They might argue that we should reject inclusive environmental ethics because they are radically incomplete and cannot provide definitive reason even to address climate change. Section 3 considers a possible response to this argument. For, even if inclusive environmental ethicists cannot offer definitive reason to accept their preferred climate change policies, they might develop their theories further to provide this justification. Some such ethics even be developed enough right now that they 
will allow us to make all of the necessary choices on the ground when we need to make them. Moreover, this section argues, there is reason to be optimistic about the prospects for some inclusive environmental ethics to address climate change. Finally, it suggests that its lessons may be important even for those who reject such ethics.

\section{An Argument Against Inclusive Environmental Ethics}

On inclusive environmental ethics, animals, plants, species, ecosystems and/or the biosphere have a kind of non-instrumental value. ${ }^{v}$ Their value is not, for example, reducible to their value for human freedom or interests. Even if humans would benefit from clearing the wetlands for condominiums, for instance, inclusive environmental ethicists would object that that is not a definitive reason to let them.

Granting that non-human individuals, species, ecosystems and so forth have noninstrumental value does not settle any questions about what to do if there are other things of value at stake. If, for instance, protecting wetlands conflicts with humans' interests in being free from malaria, it is not clear that we should preserve wetlands unaltered (Willott 2004).

Some environmental ethicists go further, however, to argue that concern for some parts of nature does not always trump concern for others. Those who think non-human parts of nature have non-instrumental value, for instance, often argue that human freedoms (or interests) will not always trump concern for other things that matter. ${ }^{\mathrm{vi}}$ When there is conflict between minor human freedoms or interests and things of significant environmental value, it will be acceptable to do what is best for non-human parts of nature. One might argue, similarly, that concern for non-human individuals, species, ecosystems and so forth does not always trump concern for the other non-human parts of 
nature. So, any way of dealing with climate change that only protects some parts of nature may fail to protect many things that matter.

Some environmental ethicists are not inclusive (Schmidtz 2002c). Some think only some parts of nature have non-instrumental value or that concern for some parts of nature always trumps concern for other parts of nature (Singer 1993; Leopold 1949). Peter Singer, for instance, seems to think that other things only have value insofar as they are important for the interests of sentient creatures (Singer 1993). Similarly, Aldo Leopold suggests that we should care for individuals, species, and ecosystems only insofar as doing so promotes the integrity, stability, and beauty of the biosphere (Leopold 1949; Callicott 1988; Attfield 1999).

This article provides no objection to these ethics. For, many of these (less inclusive) environmental ethics can provide definitive reason to address climate change, at least in principle (Gardiner 2009a). ${ }^{\text {vii }}$ On Singer's theory, for instance, we might just need to choose the climate change policy that maximizes utility for all sentient creatures. $^{\text {viii }}$

This article only considers what someone who accepts the following propositions can say about climate change: 1) Many parts of nature -- individuals, species, ecosystems and so forth -- have some non-instrumental value and 2) concern for some of these things does not always trump concern for others. It argues that, because such inclusive environmental ethics are radically incomplete, they do not provide definitive reason even to address climate change right now.

This inquiry is important, in part, because many environmental ethicists are at least inclined towards inclusive ethics. Few are explicit about whether or not they are 
committed to the view. But, many environmental ethicists have at least some sympathy for components of the view (Hassoun 2009b; Jamieson 1997; Gardiner 2004; Carafo 2002). ${ }^{\text {ix }}$ Furthermore, it should be surprising if this article can show that inclusive environmental ethics cannot provide definitive reason even to address climate change right now. For, one might see much of the work in environmental ethics as providing resources from which inclusive environmental ethicists could draw in creating good climate change policy. One might even think that an inclusive environmental ethic would be the most promising basis for justifying environmentally friendly climate change policy right now. For, these ethics embrace many environmental values.

\section{Inclusive Environmental Ethics and Climate Change Policy ${ }^{\mathbf{x}}$}

It might initially seem that inclusive environmental ethicists can just add concern for all of the things they care about to an anthropocentric liberal theory to arrive at adequate climate change policy. Where, a climate change policy is just an answer to the question "What should humans do, if anything, about climate change?". xi After all, environmental problems like climate change pose non-negligible risk of serious harm to many non-human individuals, species, and ecosystems (Gardiner 2004). In fact, there is mounting evidence that climate change is likely to cause significant problems for the majority of things that matter to inclusive environmental ethicists (IPCC, 2007 2007, 20). Perhaps these ethicists can tell us that we not only have reason to address climate change when it threatens to undermine human freedom but when it threatens non-human individuals, species, ecosystems and so forth (Hassoun 2009b).

Unfortunately, inclusive environmental ethicists cannot just add concern for all of the things they care about to an anthropocentric liberal theory to arrive at adequate 
climate change policy. ${ }^{\text {xii }}$ Although climate change may harm many individuals, species, ecosystems, and so forth, it may benefit yet other parts of nature in the process. ${ }^{x i i i}$ If, however improbably, anthropogenic climate change brings about the next ice age, arctic ecosystems and their inhabitants will flourish, though tropical ones and deserts will disappear. ${ }^{\mathrm{xiv}}$ However climate change alters the biosphere it will create problems for some (at least existing ${ }^{\mathrm{xv}}$ ) individuals and species, but be good for others (Outwater 1996; Whyte 2002). Climate change will also have some positive and some negative effects on (existing) ecosystems and the biosphere (IPCC, 2007 2007, 20). Inclusive environmental ethics are radically incomplete; although they can provide some reasons in favor of mitigating climate change, they also provide reasons not to mitigate climate change. They provide similarly conflicting reasons for and against implementing more specific climate change policies. Inclusive environmental ethics do not tell us where the weight of reason lies. So they do not, right now, provide definitive reason even to address climate change.

This argument is probably strongest when applied just to the choice between different mitigation strategies as opposed to the choice of mitigating vs. letting climate change proceed unchecked. Without a theory that is worked out in a lot of detail, it will be hard to tell whether it is best to, for instance, use solar energy or wind power to mitigate climate change. So, even if inclusive environmental ethicists do not have a problem justifying their choice of mitigating climate change (vs. not mitigating it), they might still have a problem in justifying the particular mitigation strategies they prefer.

The problem for inclusive environmental ethicists only gets worse if they care about more than climate change's impact on existing parts of nature. Consider beaver and elephants. Many environmental ethicists argue that beaver are important precisely 
because they flood the plains and create wetlands, though some individuals that prefer plains suffer in the process (UN 2008). Similarly, some environmental ethicists want to protect elephants even though they threaten endangered species like rhino and baobab trees when they tear down forests (Hassoun and Wong forthcoming; Whyte 2002). These ethicists might maintain that elephants' destruction is creative - they open the vast savannah, exerting adaptive pressure on other species, enriching the earth by creating new ecosystems (Norton 1987). Just as beavers create wetlands out of prairies and elephants create plains out of forests, climate change will replace some ecosystems with others. Climate change, like beavers and elephants, may open up new evolutionary niches, making ecosystems more dynamically and resiliently stable (Norton 2002).

Climate change may even act like early cyanobacteria. These anaerobic photosynthesizers reproduced so prolifically that they used up most of the carbon dioxide existing individuals and species needed to survive (Croal 2005). In doing so, however, they produced a lot of oxygen, making it easier for aerobic organisms to evolve. Climate change may give life to a whole new world. Consider how one scientist put the point:

To the conservation biologist, there is little positive to be said about extinction. From an evolutionary perspective, however, extinction is a double-edged sword. By definition, extinction terminates lineages and thus removes unique genetic variation and adaptations. But over geological time scales, it can reshape the evolutionary landscape in more creative ways, via the differential survivorship of lineages and the evolutionary opportunities afforded by the demise of dominant groups and the postextinction sorting of survivors (Jablonski 2001, 5393).

Even extinction has its upside. ${ }^{x v i}$

Perhaps those who care about many things can reject this last move. Maybe they can justify taking a much more limited temporal perspective. They might, for instance, value different parts of nature over different time scales (Norton 2003). 
There are two problems with this suggestion. First, it is not clear that inclusive environmental ethicists can provide a non-arbitrary way to value different parts of nature over different time scales. Second, even if they can do so, they may not be able to offer definitive reason to accept their preferred climate change policies. For, we have seen how climate change (and, hence, different climate change policies) will affect existing individuals, species, ecosystems, and so forth differently. ${ }^{\text {xvii }}$

Nothing in the above argument (or the rest of this article) requires a commitment to consequentialism. As stated, the argument points to the different benefits and harms climate change will bring to existing individuals, species, and so forth. It can, however, be recast in different theoretical frameworks. So those who prefer to talk in terms of rights violations, for instance, can do so. Similarly, it does not matter if inclusive environmental ethicists deny that it is a good thing to bring new species, ecosystems, and so forth into existence. ${ }^{\mathrm{x} v i i i}$ As long as they grant that our actions impact at least existing individuals and so forth in ways that merit consideration, a revised version of the above argument will apply.

Finally, none of this commits those who care about many things to embracing a biocentric ethic on which most or all parts of nature (e.g. individuals or species) merit equal consideration or respect. So the problem for inclusive environmental ethics is not just a version of the problem that plagues (egalitarian) biocentric ethics (Taylor 1986; Davion 2006). ${ }^{\text {xix }}$ Inclusive environmental ethicists who are not biocentrists need not be particularly concerned with "the morality of swatting pesky flies, mowing the lawn, [or] building patios" (Davion 2006, 126). For, recall that these ethicists need only hold the following propositions: 1) many parts of nature -- individuals, species, ecosystems and so 
forth -- have some non-instrumental value and 2) concern for some of these things does not always trump concern for others.

The problem for inclusive environmental ethics just stems from the fact that they are radically incomplete; although they can provide some reasons in favor of particular climate change policies, they also provide reasons not to implement those policies. They do not tell us where the weight of reason lies. Inclusive environmental ethicists do not have a complete theory that can tell us what to do about climate change.

Objections, Replies, and the Anthropocentric Liberal's Argument

The rest of this section will consider several possible responses to the above argument. First, it will consider whether the current episode of climate change, because it is anthropogenic, is unlike other episodes of climate change in problematic ways. Next, it will consider arguments that emphasize the harm that climate change will cause many parts of nature. This section will conclude that none of these responses is successful. So, anthropocentric liberals may reject inclusive environmental ethics because they cannot provide definitive reason to accept their preferred climate change policies.

Consider, first, how inclusive environmental ethicists might appeal to one of $\mathrm{J}$. Baird Callicott's arguments for addressing other anthropogenic environmental disturbances. Maybe "the problem with anthropogenic disturbances... is that they are far more frequent, widespread, and regularly occurring than are non-anthropogenic disturbances, they are well out of the spatial and temporal range of disturbances experienced by ecosystems over evolutionary time" (Callicott 2001, 215). Because the current episode of climate change is anthropogenic, it may be unnatural in a problematic way (Mathews 2002). 
It is not clear, however, that anthropogenic climate change is likely to occur at different spatial and temporal scales than non-anthropogenic climate change. In fact, we know that the climate has changed just as rapidly in the past as it appears to be changing now and scientists predict similar results (National Environmental Satellite, Data, and Information Service 2008). So Callicott's argument does not work in the present case, even though many other anthropogenic disturbances occur at different spatial and temporal scales than corresponding non-anthropogenic disturbances.

Even if anthropogenic climate change is different in some respects from past climatic shifts, that may be good. These differences may benefit some species or ecosystems, for instance. Nor will it help to grant that natural processes are better than anthropogenic ones (a difficult proposition to support). Inclusive environmental ethicists believe many things matter besides processes. So, more argument is necessary to conclude that it is wrong for us to alter the climate.

Inclusive environmental ethicists might argue that it does not matter what good our actions do for individuals, species, ecosystems and so forth. Perhaps what matters is that we do not harm these things. Since the current episode of climate change is anthropogenic, we are harming some individuals, species, ecosystems and so forth. So, perhaps, we have reason to stop contributing to climate change and, perhaps, to mitigate the damage we have caused.

It is at least plausible, however, that we should sometimes promote the interests of sentient creatures, preserve species, and restore ecosystems or the biosphere. Even some who do not qualify as animal rights activists argue, for instance, that we should promote 
our pets' health (Calicott 1988). Others suggest preserving species threatened by nonanthropogenic environmental problems (Jamieson 1997). ${ }^{\mathrm{xx}}$

Further, mitigation will harm some of the things that matter to inclusive environmental ethicists. If, for instance, people started using solar energy rather than fossil fuels to mitigate climate change, that would probably harm some ecosystems and species. For, photovoltaic panels contain some toxic semi-conducting materials (US Department of Energy 2009). ${ }^{x i}$ In fact, mitigation will harm some parts of nature on any plausible baseline for harm. ${ }^{\text {xii }}$ It will make some individuals, species, ecosystems and so forth worse off than they would have been if we had never emitted any green house gasses. It will even make some of these things worse off than they would have been if we had never been on the planet at all. Some birds that fly into the wind-farms would have survived, but for our having existed, caused climate change, and put up the farms to mitigate its impact. ${ }^{\text {xiii }}$

Perhaps inclusive environmental ethicists can defend mitigation (in general), even with an incomplete ethic. They might give something like the following argument in favor of mitigation.

1) There will be more harms and more severe harms to things that matter if we do not mitigate climate change than if we do.

2) On inclusive environmental ethics there is an obligation not to harm individuals, species, ecosystems, and so forth.

C) So, we should mitigate climate change.

Inclusive environmental ethicists might suggest that they do not need to say any more because, given their commitments, it is easy to see why mitigation is necessary. 
Even if this argument for mitigation in general goes through, inclusive environmental ethicists may still have a problem justifying the particular climate change policies they prefer. For, much more detail may be necessary to arbitrate between these strategies.

It is not clear, however, that the above argument can even support mitigation in general. It contains an important ambiguity. It is possible to understand its first premise in two ways - as implicitly normative or purely descriptive. If it is implicitly normative and is supposed to entail that the harms climate change will bring are impermissible, it requires more defense. Why think the number and kind of harms climate change will bring will be greater in any morally relevant sense than the number and kind of harms mitigation will bring? If the claim that the number and kind of harms climate change will bring will be greater than those of mitigation is purely descriptive, however, then it is not clear why 1) and 2) are supposed to entail 3). To make this argument valid, rather than 2), inclusive environmental ethics require something like:

3) If there will be more harms and more severe harms to things that matter if we do not mitigate climate change than if we do, we should mitigate.

But then we return to our original question: Why do the number and severity of the harms that will occur if we do not mitigate outweigh or trump the other harms (and possibly benefits) that mitigation will bring? If inclusive environmental ethicists want to engage with others who do not agree that we must mitigate climate change for this reason, they must answer this question. They cannot just appeal to 3) -- the brute principle that we should mitigate the greatest number and most severe harms in this case. Nor can inclusive environmental ethicists simply assert that any reasonable environmental ethic has to 
provide reason to mitigate climate change (Shue 2008; Hassoun 2009b; Jamieson 1997; Gardiner 2004). ${ }^{\text {xiv }}$ They need an explanation to engage with others who do not simply see this truth, not just a desideratum.

Although nothing we have said so far demands that inclusive environmental ethicists adopt consequentialism, they might do so to support the third premise above. ${ }^{\mathrm{xxv}}$ On some versions of consequentialism, for instance, we should minimize the sum of harm. These ethicists could then give the above argument in favor of mitigating climate change. ${ }^{x v i}$

We need to know more about the kind of consequentialism at issue to decide whether it is plausible, however. Do all individuals, species, ecosystems and so forth count equally? Or, do harms to some things (e.g. humans) count more than harms to other things (e.g. mosquitoes)? How much more?

Environmental ethicists have done some work that might provide answers to these questions. Inclusive environmental ethicists might, for instance, appeal to Paul Taylor's work on how to weigh and balance the interests of members of different species. For, his theory is perhaps the most developed (though Taylor does not qualify as a consequentialist or an inclusive environmental ethicist). He gives a deontological theory and does not think species, ecosystems, or the biosphere have non-instrumental value. Taylor suggests a version of species egalitarianism but he argues that, in cases of conflict, it is acceptable to sacrifice nonhuman interests for basic human interests (Taylor 1981, 264-265). He believes humans can invoke a right to self-defense in such cases as long as they try to minimize these conflicts. In other cases, he suggests satisfying only non-basic human interests that are compatible with an attitude of respect for nature in the least 
harmful way. He also believes we should advance the basic interests of all equally and compensate for undue harms and unjust inequalities in the distribution of resources (Taylor 1981).

Taylor's principles are not plausible, however. It is not clear, for instance, that we should be so egalitarian. As David Schmidtz points out, species egalitarianism seems to suggest that it often makes no difference what we kill (Schmidtz 2002c, 97). It is not plausible to think that killing a cow or a turnip carries the same moral weight. Nor is it clear that we should be just as inclined to do research on a chimpanzee as a mouse.

Even if some inclusive ethicists disagree, however, and want to embrace such egalitarianism, they must say more. Otherwise, they cannot provide a complete justification even for mitigating climate change. They must explain how to take the noninstrumental value of species, ecosystems, and the biosphere into account as well as the interests of individuals.

Unless I am overlooking something in the environmental ethics literature, inclusive environmental ethicists must do further work to justify the climate change policies they prefer. ${ }^{\text {xxvii }}$ Even to decide whether climate change is generally good or bad, they need an account of how much each of its effects matters or which considerations trump all others. Would it be bad if climate change caused massive extinctions but increased biodiversity, benefitting the biosphere? Would it be good if climate change saved some species from extinction but harmed many individuals in the process? While this article will say more about the answers to these questions below, they are difficult and divisive (Schmidtz 2002a; Schmidtz 2002c; Rolston, 2002; Singer, 1993). There is no well worked out theory that takes into account all of the things inclusive 
environmental ethicists care about and provides determinate answers to all of these

questions. ${ }^{\text {xxviii }}$ So, inclusive environmental ethics are radically incomplete; although they can provide some reasons in favor of particular climate change policies, they also provide reasons not to implement those policies. They do not tell us where the weight of reason lies.

Because inclusive environmental ethics are radically incomplete, even if the climate change policies their advocates prefer are morally permissible, inclusive environmental ethics cannot justify these policies right now. Even worse, a different (e.g. anthropocentric liberal) theory may provide this justification. So, anthropocentric liberals might conclude that this argument gives us reason to reject inclusive environmental ethics.

\section{Response to the Argument Against Inclusive Environmental Ethics}

This section responds to the anthropocentric liberals' argument. It suggests that, even if inclusive environmental ethicists cannot offer definitive reason to accept their favorite climate change policies right now, such ethics might be developed further so that they can justify climate change policies in the future. Moreover, inclusive environmental ethics may, right now, provide all the resources we need for an adequate response to climate change. Finally, this section argues that there is reason to be optimistic about the prospects for some inclusive environmental ethics to address climate change.

The anthropocentric liberal's argument went something like this:

1. There is no compelling inclusive environmental ethic that takes into account all of the relevant considerations and tells us what to do about climate change. 
2. So even if the climate change policies their advocates prefer are morally permissible, they cannot be justified by inclusive environmental ethics.

3. Hence, we should reject inclusive environmental ethics.

There are different ways of locating the problem with this argument. Initially, the move from this argument's first to second premise might seem most questionable. This article has only argued that inclusive environmental ethicists cannot provide definitive reason to accept their preferred climate change policies right now. Interpreting the second premise in this way, however, the argument's biggest problem is in the move from this premise to its conclusion. For, it is possible that their ethics can be developed enough to provide all the resources we need for an adequate response to climate change. Some such ethics even be developed enough right now that they allow us to make all of the necessary choices on the ground when we need to make them. Suppose, for instance, that climate change would expand the range of a species in the Sonoran desert that would otherwise hover on the verge of extinction. An inclusive environmental ethic may give us reason to mitigate climate change and protect that species in another way. We might, for instance, be able to protect the species by expanding the Sonoran National Park. Of course, creating a nature reserve will require (scarce) resources, but it is far from clear that we cannot both mitigate climate change and create the necessary reserves etc. There may be policies that can mitigate any important conflicts between the things that matter to inclusive environmental ethicists.

Anthropocentric liberals might argue, however, that we should reject inclusive environmental ethics because no climate change policy will be morally permissible on any such ethic. This article started by assuming that there will be winners and losers from 
climate change policies. If this assumption is reasonable, anthropocentric liberals might argue, so is the assumption that no climate change policy will be morally permissible on any inclusive environmental ethic. On inclusive environmental ethics (almost) everything matters. Climate change is a global problem likely to impact almost all of these things. There are limited resources for dealing with environmental problems. Though we might be able to protect the climate and wetlands, we cannot protect the climate and everything else that matters to inclusive environmental ethicists.

The scope of climate change and inclusive environmental ethicists' concern certainly makes it seem likely that no climate change policy will be morally permissible on any inclusive environmental ethic. But, just as global problems present many challenges, the global scope of possible policy responses to these problems present many ways of addressing these challenges. In a small community, for instance, it may turn out that it is only possible to protect the environment or jobs (e.g. logging may be the only viable industry in the area). If the loggers can get different jobs in the city, however, that might be morally permissible on an inclusive environmental ethic. ${ }^{\text {xix }}$ The claim that no climate change policy will be morally permissible on any inclusive environmental ethic is unwarrantedly strong. Though we might not be able to protect the climate and everything else that matters, there may be some morally permissible policies on some inclusive environmental ethics.

Besides, the fact that a theory is incomplete and cannot provide definitive reason to accept any climate change policies right now is not a reason to reject it. For many theories are incomplete without being valueless. Incomplete theories may provide insight. They may even provide important guidance. Inclusive environmental ethics tell us a lot 
about the nature of environmental value and provide reasons (though, perhaps, not definitive reasons) in favor of many policies. Theoretical incompleteness may just be a reason to reject a theory's application, rather than the theory itself. ${ }^{x x}$

Finally, inclusive environmental ethicists might even go further to argue that we should be optimistic about the prospects for some inclusive environmental ethics to address climate change. Without a complete theory, it is not clear how inclusive environmental ethicists can provide a deductive argument for this conclusion. They might, however, challenge a common presumption that may undergird the anthropocentric liberal's skepticism. Inclusive environmental ethicists might challenge the presumption that it is often impossible to protect all of the things that matter to them. In doing so, they can also illustrate a general strategy for addressing climate change implementing their preferred policies and addressing potential problems as they arise.

Many environmental ethicists (amongst others) presume that it is often impossible to protect all of the things that matter to inclusive environmental ethicists (Rolston 2002; Sagoff 1984; Callicott 1980). Some presume, for instance, that we must choose between protecting people and other parts of nature. Others argue that we must sometimes choose whether to protect individuals or species and ecosystems (Schmidtz 2002a; Schmidtz 2002b). If this article can provide reasons to doubt these authors' examples, anthropocentric liberals should think twice before they assert that there will be insurmountable difficulties in dealing with climate change.

Consider, first, how it is possible to respond to the claim that there is no way to protect people's basic interests (including their interest in freedom) and other parts of nature (Rolston 2002). David Schmidtz makes the case that the interests of people and 
nature align much more closely than many have thought. He does this by considering the purported conflict between preservationist and conservationist theories (Schmidtz 2002a; Schmidtz 2002b). Preservationists often argue for "no use" policies because they believe we should preserve nature (protecting it even if doing so is not in human interests). Conservationists often argue for "wise use" policies that conserve nature (protecting it whenever doing so is in human's interests). Schmidtz suggests that we must sometimes preserve nature to conserve it. In some circumstances, wise use may be no use at all. It may not be wise to even consider using nature if there is some risk that doing so will expose us to unknown dangers. But, Schmidtz suggests, to really protect nature, we sometimes have to use it wisely. Hunting may, for instance, be a good way of protecting elephants. Hunters will pay to maintain nature reserves that would otherwise be turned into towns (Schmidtz 2002a; Schmidtz 2002b). ${ }^{\mathrm{xxi}}$

Schmidtz suggests that the real tension is not between saving people and nature but between saving non-human individuals and protecting species and ecosystems. He recalls the debate between animal rights activists and forest rangers concerned about species preservation and the Yellowstone ecosystem. When a herd of sheep in Yellowstone got pink-eye, the rangers did not save the sheep. They let nature take its course. Animal rights activists were incensed especially since, a few years before, the rangers had gone to heroic lengths to save a grizzly and her cub trapped on a quickly melting island of ice. The rangers argued, however, that it was important to save the grizzly and let the sheep die to preserve the health of the species and the Yellowstone ecosystem. Similarly, Schmidtz argues, only animal rights activists should object to 
hunting in national parks when hunting is the best way to preserve wildlife (Schmidtz 2002a; Schmidtz 2002b).

But, even the tension between animal rights activists and others who care about nature may be overstated (Callicott 1980; Sagoff 1984; Callicott 1988). Perhaps animal rights activists could have convinced the rangers to let them transport the sheep to another reserve capable of supporting them (perhaps Yosemite was low on sheep). And, if the rangers' objection was to letting the sheep reproduce in the wild at all (perhaps their main concern was about the natural evolution of the species) the sheep might be sterilized first or kept as pets. Similarly, eco-tourism rather than hunting in Africa might preserve both individual animals and other parts of the natural world. And some argue that even animal rights activists should sometimes support killing or letting individuals die (Varner 1995).

The cases above illustrate how we might sometimes protect all of the things that matter on some inclusive environmental ethics even though it is common to assume that we cannot. They provide some (admittedly tentative) reasons for optimism. For, they illustrate how there are overlooked alternatives to many purportedly irresolvable conflicts between protecting things that matter to inclusive environmental ethicists. The above cases demonstrate how some such ethics can resolve a range of environmental problems. ${ }^{\text {xxii }}$ They illustrate a general strategy addressing climate change - dealing with potential problems for climate change policies as they arise - what conservation biologists call adaptive management. To pursue adaptive management policy makers tentatively implement a policy, test its impact on different variables of interest, and then repeat the process until they find an acceptable policy. ${ }^{\text {xxxii }}$ Perhaps inclusive 
environmental ethicists can use this strategy to address climate change. They might look at how the policies they implement affect everything they care about and try to adjust them in light of the evidence. There is reason for optimism.

Some inclusive environmental ethicists cannot produce permissible climate change policies. An inclusive environmental ethicist who holds, for instance, that we can never harm individuals may not be able to license any climate change policies. Almost any climate change policy we implement will harm some individuals (recall the bird and the windmill). Nevertheless, some inclusive environmental ethics can probably license some climate change policies.

Perhaps the above argument presupposes that inclusive environmental ethicists have a theory that can justify climate change policy. After all, if it is possible to say that some policies are acceptable, they must have a principle explaining why that is so. The set of principles licensing an acceptable policy is just what inclusive environmental ethicists were supposed to be missing.

For the above argument to work, it must be the case that some plausible inclusive environmental ethics could endorse the policies suggested above. But, that is not the same as presupposing a complete inclusive environmental ethic. Rather, the above arguments suggest that such an ethic might, plausibly, support these policies. (There may be many plausible ethics that would support these policies. $)^{\mathrm{xxxiv}}$

Perhaps one could argue that this section provides, rather than presupposes, the complete inclusive ethic the previous section claimed was missing. Maybe we should pursue adaptive management. Perhaps we should implement the policies that seem most 
reasonable in light of existing evidence and theories and then address any problems that arise for things that matter to inclusive environmental ethicists (Lee 1999).

Although I would be happy if this were so, it is not clear that this section has completely dissipated the problem for inclusive environmental ethics. Nor, without a much more developed theory, is it clear that these ethics can provide definitive reason to attempt adaptive management. Adaptive management seems utterly reasonable in the present case, but some of the things that matter on inclusive environmental ethics might do better if we took a different approach (Lee 1999). The arguments above just provide reason to be optimistic about the prospects for such ethics to adequately address climate change. Inclusive environmental ethicists may be able to advocate adaptive management but there may be other ways of addressing climate change they could reasonably support as well. ${ }^{\mathrm{xxx}}$

To recap, this section suggested that the anthropocentric liberals' argument for rejecting inclusive environmental ethics traded on an ambiguity. Although inclusive environmental ethicists cannot offer definitive reason to accept their preferred climate change policies, their theories might be developed further in order to provide this justification. To reject such ethics anthropocentric liberals must deny the follow claim: If 1) there is no reason to think the theory can never justify good climate change policies, 2) it may be acceptable even if it is incomplete and cannot provide these policies right now. Furthermore, this section suggested that we should be especially hesitant to reject incomplete theories when 3) they provide some important guidance or 4) we have reason to be optimistic about their prospects for providing all of the guidance we need. This section argued that inclusive environmental ethics may be able to provide justification for 
good policy responses to climate change. It also argued that they may provide some guidance right now and we have reason to be optimistic about their prospects for providing all of the guidance we need. So, inclusive environmental ethicists might maintain their theories, even though they are incomplete and cannot tell us what to do about climate change right now.

This article's lessons might generalize beyond inclusive environmental ethics. Any incomplete pluralistic theory, on which more than one thing matters, may face a problem similar to the problem that afflicts inclusive environmental ethics. Unless a theory is comprehensive -- explaining how all of the things that matter should be taken into account -- it may not provide definitive reason to accept any climate change policies. ${ }^{\text {xxvi }}$ Even some anthropocentric liberal theories may have this problem. The climate change policy that best promotes some human freedoms may undermine others. Depending on how emissions permits are allocated, this response to climate change may make it more difficult for some to secure important positive freedoms or basic capabilities. ${ }^{\text {xxxvii }}$ Liberal theories concerned about both the freedom to trade and basic capabilities must tell us how we should take these freedoms into account when it is difficult to protect both. Otherwise, they cannot provide a definitive evaluation of policies like these.

Inclusive environmental ethics are, however, more likely to suffer from the kind of problem this article has sketched than anthropocentric liberal ones. For, some anthropocentric liberal theories only embrace a concern for one kind of human freedom. Inclusive environmental ethics are, by definition, concerned about more than one thing. ${ }^{\text {xxxviii }}$ 
Furthermore, even though inclusive environmental ethics are not the only ethics that have the problem this paper has sketched, that they have it is both surprising and significant. For, until now, environmental ethicists have been the ones worrying that their competitors cannot adequately address climate change, rather than the other way around. Moreover, in virtue of their comprehensiveness, one might have expected inclusive environmental ethics to be best for dealing with climate change. But it is precisely because these ethics are comprehensive that they have this problem.

Finally, though the kind of problem this article has set out for inclusive environmental ethicists is general, at least the core of its response to the anthropocentric liberal's argument is general as well. It is not clear that we should reject a theory just because it cannot right now provide definitive reason to accept any climate change policies. Rather, such theories might be developed further so that they can justify some climate change policies. Moreover, such theories might be able to tell us how to make all of the decisions that we must actually make on the ground. So, if there are good reasons to believe what these theories $d o$ say, creativity rather than despair may be on order. ${ }^{\text {xxxix }}$

\section{Conclusion}

Many versions of liberalism give us definitive reason to mitigate climate change. Environmental ethicists argue, however, that at least anthropocentric versions of liberalism do not account for many things that matter. These critics suggest that individuals of other species, species, ecosystems and so forth have a kind of value beyond what they contribute to protecting human freedom. Further, on inclusive environmental ethics, concern for some parts of nature does not always trump concern for others. 
This article has argued that, although there is probably something to inclusive environmental ethics, they have a different problem. When there are many things of value, figuring out what to do can be extremely difficult. Even though climate change is likely to harm many species and ecosystems, for instance, it will probably benefit some. Inclusive environmental ethicists lack a compelling theory taking all these different considerations into account. Without this theory they cannot provide definitive reason to accept their preferred climate change policies. So, anthropocentric liberals might conclude, that we should not accept such ethics.

This article does not provide a solution to the inclusive environmental ethicists' problem - they lack a complete and plausible theory that can provide definitive reason to accept any climate change policies right now. It does, however, suggest that anthropocentric liberals cannot use this conclusion to conclude that we should reject inclusive environmental ethics. Inclusive environmental ethics might be developed to justify the climate change policies their proponents prefer. Further, their theories may provide all the resources we need for an adequate response to climate change right now.

To support this last line of thought, this article considered how inclusive environmental ethicists might go further to argue that we should be optimistic about the prospects for some inclusive environmental ethics to address climate change. The environmental ethics literature is replete with purported dilemmas for such ethics. Some argue, for instance, that we must either save people or nature (Rolston 2002). Others suggest that we must choose between saving individuals and saving species or ecosystems (Schmidtz 2002b). This section argued, however, that we should not assume that such conflicts are irresolvable. When we lack a complete theory, it may be best to try 
to come up with creative responses to environmental problems compatible with the moral knowledge we do have. We may, for instance, find good policies that can protect all of the things that matter to inclusive environmental ethicists. Suppose the best alternative energy source harms some valuable ecosystems -- say, wetlands. A good climate change policy might rely upon that energy source, while at the same time advancing wetland conservation programs. It will probably be hard for inclusive environmental ethicists to decide what to do about climate change, but we should not assume that inclusive environmental ethics cannot justify doing anything.

I am not entirely sure the problem this article raises for inclusive environmental ethics is genuine. Nor am I sure that the suggested response to the anthropocentric liberal's claim that this problem gives us reason to reject inclusive environmental ethics is a good one. Nevertheless, I hope that this article's arguments merit response and further exploration. Moreover, whether or not these arguments work in the present case, they may be of interest even to those who reject inclusive environmental ethics. For many theories endorse more than one kind of value and lack principles for resolving all of the conflicts that may arise between these values. Even some anthropocentric liberal theories may have this problem. 


\section{References}

Adams, P. 2009. Email Correspondence. 6/9/2009.

Attfield, R., 1999. Ethics of the global environment. Edinburgh: Edinburgh University Press.

Attfield, R., 2002. The good of trees. In: D. Schmidtz and E. Willott eds. Environmental ethics: what really matters, what really works. Oxford: Oxford University Press.

Callicott, B., 2001. The land ethic. In: D. Jamieson ed. The companion to environmental philosophy. Oxford: Blackwell Press, 215.

Callicott, B., 1988. Animal liberation and environmental ethics: Back together again, In: E. Hargrove ed. The animal rights/environmental ethics debate: the environmental perspective. Albany: State University of New York Press.

Callicott, B., 1980. Animal liberation: A triangular affair, Environmental Ethics 2, 311328.

Cafaro, P. 2002. Rachel Carson's environmental ethics, Worldviews: Global Religions, Culture, and Ecology, 6, 58-80.

Carson, R., 1962. Silent spring. Norwalk: Easton Press.

Croal, L., 2005. FE(II) oxidation by anaerobic phototrophic bacteria: Molecular mechanisms and geological implications. Dissertation, California Institute of Technology. Retrieved January 5, 2008. Available online at: $<$ http://etd.caltech.edu/etd/available/etd-06062005011632/unrestricted/LRC_Thesis.pdf>.

Davion, V. 2006. Itch scratching, patio building and pesky flies: Biocentric 
individualism revisited. Environmental ethics, 28, 2, 115-128.

Feinberg, J. 1984. Harm to others. Oxford: Oxford University Press.

Frankfurt, H. 1988. The importance of what we care about: Philosophical essays. Cambridge University Press: Cambridge.

Gardiner, S., 2004. Ethics and global climate change, Ethics, 114, 555-600.

Gardiner, S., 2009a. Climate change as a global test for contemporary political institutions and theories. University of Washington Working Paper. Seattle: University of Washington.

Gardiner, S., 2009b. Rawls and climate change: Does Rawlsian political philosophy pass the global test? University of Washington Working Paper. Seattle: University of Washington.

Hassoun, N. and Wong, D., forthcoming. Conserving nature; preserving identity, In: Indigenous knowledge and cultural property: the ethics of cultural and environmental sovereignty and stewardship. Tucson: University of Arizona Press.

Hassoun, N., 2008a. World poverty and individual freedom. American philosophical quarterly, 45, 2, 191-198.

Hassoun, N., 2009a. Nanotechnology, enhancement, and human nature. Nanoethics: Ethics for technologies that converge at the nanoscale, 2, 3, 265-275.

Hassoun, N., 2009b. Free trade and the environment. Environmental ethics, 31, 51-66.

Hassoun, N., 2009c. The minimally good human life account of needs. Carnegie Mellon University Working Paper. Pittsburgh: Carnegie Mellon University.

Hassoun, N., forthcoming. Free trade, poverty, and inequality. The Journal of Moral Philosophy. 
Hayward, T. 2009. International political theory and the global environment: Some critical questions for liberal cosmopolitans. Journal of social philosophy, 40, 2, 276-295.

IPCC, 2007. Summary for policymakers. In: Climate change 2007: Impacts, adaptation and vulnerability. contribution of working group ii to the fourth assessment report of the intergovernmental panel on climate change, M.L. Parry, O.F. Canziani, J.P. Palutikof, P.J. van der Linden and C.E. Hanson, eds., Cambridge: Cambridge University Press. Available online at: <http://www.ipcc.ch/pdf/assessmentreport/ar4/wg2/ar4-wg2-spm.pdf>.

Jablonski, D. 2000. Lessons from the past: evolutionary impacts of mass extinctions. Colloquium paper presented at the National Academy of Sciences colloquium: The future of evolution. March, 16-20. Available online at: $<$ http://64.233.169.104/search?q=cache:df0MEHVYOMgJ:geosci.uchicago.edu/p eople/faculty/pdfs/PNAS01.pdf+to+the+conservation+biologist,+there+is+little+ positive+to+be+said+about+extinction $\&$ hl=en\&ct=clnk\&cd=4\&gl=us\&client=fir efox-a>.

Jamieson, D., 2005. Adaptation, mitigation, and justice, Perspectives on climate change: science, economics, politics, ethics. W. Sinnott-Armstrong and R. Howarth eds. Advances in the economics of environmental resources 5. New York: Elsevier. Jamieson, D., 1997. Animal liberation is an environmental ethic. Draft Paper forthcoming in Environmental values. University of Colorado: Boulder. Available online at: <http://www.acad.carleton.edu/curricular/ENTS/faculty/dale/dale_animal.html>. Jamieson, D., 2003. Normative ethics. A companion to environmental ethics. Oxford: Blackwell Press. 
Joyce, T. and Keigwin, L., 2003. Are we on the brink of a new little ice-age? Woods Hole Oceanographic Institution. Available online at: <http://www. whoi.edu/page.do?pid=12455\&tid=282\&cid=10046>.

Lee, K. N. 1999. Appraising adaptive management. Conservation ecology, 3, 2. Available online at: <http://www.consecol.org/vol3/iss2/art3/>.

Leopold, A., 1949. A sand county almanac with essays on conservation from Round River. New York: Balantine Books, 101-103.

Lomasky, L., 1987. Persons, rights, and the moral community. New York: Oxford University Press, Chap. 5.

Machan, T., 2001. The perils of positive rights. The freeman: ideas on liberty, 51, 4. Mathews, F., 2002. Letting the world grow old: An ethos of countermodernity. In: D. Schmidtz and E. Willott eds. Environmental ethics: What really matters, what really works. Oxford: Oxford University Press, 221-230.

Mayell, H., 2002. Climate studies point to more floods in this century. National geographic news. January, $30^{\text {th }}$ Available online at: <http://news.nationalgeographic.com/news/2002/01/0130_020130_greatfloods.ht $\mathrm{ml}>$.

Midgley, M., 2002. Duties concerning islands In: D. Schmidtz and E. Willott eds. Environmental ethics: What really matters, what really works. Oxford: Oxford University Press.

Naess, A., 2005. The selected works of Arne Naess. Harold Glasser ed. Volumes 1-10 New York: Springer. 
National Environmental Satellite, Data, and Information Service, 2008. A Paleo perspective on abrupt climate change. U.S. Department of Commerce. Suitland, MD. Original online publication May, 2004. Updated June, 2008. Available online at: <http://www.ncdc.noaa.gov/paleo/abrupt/index.html> .

Norton, B., 1987. Why preserve natural variety? New Jersey: Princeton University Press.

Norton, B., 2002. Fragile freedoms. In: D. Schmidtz and E. Willott eds. Environmental ethics: what really matters, what really works. Oxford: Oxford University Press, 501-505.

Norton, B., 2003. Searching for sustainability: interdisciplinary essays in the philosophy of conservation biology. Cambridge: Cambridge University Press.

Nozick, R., 1974. Anarchy, state, and utopia. New York: Basic Books.

Nussbaum, M., 2006. Frontiers of justice: Disability, nationality, species membership. Cambridge: Harvard University Press.

Nussbaum, M., 2007. Human rights and human capabilities. Harvard human rights journal, 20, 24.

Outwater, A., 1996. Natural history of beavers [Electronic version]. Excerpt from chapter 2 of Nature's hydrologists in water: A natural history. Retrieved October 14, 2007, from: http://www.shawsheen.org/Beavers/Natural_History_of_Beavers/natural_history_ of_beavers.html

Rawls, J., 1979. Theory of justice. Cambridge: Belknap Press.

Joseph Raz. 1998. The Morality of Freedom. Clarendon Pres: Oxford. 
Rolston III, H., 2002. Feeding people versus saving nature. In: D. Schmidtz and E. Willott eds. Environmental ethics: What really matters, what really works. Oxford: Oxford University Press, 404-416.

Rolston III, H., 1988. Environmental ethics: Duties to and values in the natural world Philadelphia: Temple University Press.

Sagoff, M., 1984. Animal liberation and environmental ethics: Bad marriage, quick divorce. Osgoode hall law journal, 22, 2, 297-307

Schmidtz, D., 2002a. When preservationism doesn't preserve. In: D. Schmidtz and E. Willott eds. Environmental ethics: What really matters, what really works. Oxford: Oxford University Press.

Schmidtz, D., 2002b. Natural enemies: An anatomy of environmental conflict. In: D. Schmidtz and E. Willott eds. Environmental ethics: What really matters, what really works. Oxford: Oxford University Press.

Schmidtz, D., 2002c. Are all species equal? In: D. Schmidtz and E. Willott eds. Environmental ethics: What really matters, what really works. Oxford: Oxford University Press, 96-103.

Schmidtz, D. and Willott, E. 2002. Why environmental ethics? In: D. Schmidtz and E. Willott eds. Environmental ethics: What really matters, what really works. Oxford: Oxford University Press, xi.

Shue, H., 2002. Global environment and international inequality. In: D. Schmidtz and E. Willott eds. Environmental ethics: What really matters, what really works. Oxford: Oxford University Press, 394-404. 
Shue, H., 2008. Deadly delays: climate change and future generations. Energy and Responsibility: A Conference on Ethics and the Environment. April 12, 2008. Knoxville: University of Tennessee.

Singer, P., 1993. Practical ethics. Cambridge: Cambridge University Press.

Sit, V. and Taylor, B. 1998. Introduction, Statistical Methods for Adaptive Management Studies. Ministry of Forests Research Program: British Columbia. Available at: 〈http://www.for.gov.bc.ca/hfd/pubs/docs/Lmh/Lmh42.pdf >.

Sterba, J. 1995. A biocentrist fights back. Environmental Ethics, 17, 4, 361-376.

Taylor, P., 1981. The Ethics of Respect for Nature, Environmental Ethics 3: 197-218.

Taylor, P., 1986. Respect for nature. New Jersey: Princeton University Press.

The United Nations (UN), 2008. The UN works to protect endangered species. Retrieved January 4, 2008. Available online at: <http://www.un.org/works/environment/animalplanet/beaver.html>.

US Department of Energy. 2009. Implications of PV manufacturing and production. Solar Energy Technologies Program. Retrieved August 19, 2009. Available online at: < http://www1.eere.energy.gov/solar/man_pro_implications.html>.

Varner, G. 1995. Can animal rights activists be environmental ethicists? In: D. Marietta and L. Embree eds. Environmental ethics and environmental activism. Lanham, MD: Rowman \& Littlefield, 169-201

Whyte, I., 2002. Headaches and heartaches: The elephant management dilemma In: D. Schmidtz and E. Willott eds. Environmental ethics: What really matters, what really works. Oxford: Oxford University Press, 293-305. 
Willott, E., 2004. Restoring nature without mosquitoes? Restoration ecology, 12, 143153. 


\section{Acknowledgements}

The author owes thanks to Jason Matteson, Eric Hattleback, Orsolya Reich, Mandy Simons, Richard Miller, Stephen Gardiner, Alex London, Will Braynen, Clark Glymour and especially Ron Sandler and Sarah Wright for discussion and/or comments. She would also like to thank those who were kind enough to comment on her article "Nanotechnology, Enhancement, and Human Nature" as this article draws on some arguments in that one. Finally, she is also thankful to the editors and reviewers for this special issue for their detailed and insightful comments. 
i Nicole Hassoun, Carnegie Mellon University, 135 Baker Hall, Pittsburgh, PA 15213 USA,

nhassoun@andrew.cmu.edu

ii One might, of course, deny that anything has non-instrumental value, but this article will not address this kind

of skepticism.

iii Non-anthropocentric environmental ethicists believe that humans are not the only things that matter. See

(Schmidtz 2002d) for discussion.

iv For criticism of liberal ethics see (Gardiner 2009a; Gardiner 2009b; Hayward, 2009). Gardiner gives a

sophisticated critique of John Rawls' theory in particular and political theories more generally. In his general

criticism of liberalism he raises this problem, although the thrust of his critique is somewhat different.

$\mathrm{v}$ By endorsing the claim that some things have non-instrumental value, environmental ethicists need not be committing themselves to any meta-ethical views. For discussion see: (Schmidtz and Willott, 2002).

vi Richard Routley's last man argument is perhaps the most famous argument in support of this conclusion (Schmidtz \& Willott, 2002).

vii There are also many ways of resolving the inclusive environmental ethicists' problem. This article will suggest, however, that inclusive environmental ethicists lack the theory that will allow them to resolve it. See (Gardiner 2009a) for critique of high-level solutions to the climate change problem.

viii His ethic would, presumably, require radical action to address climate change. 
ix Certainly, many agree that individuals, species, ecosystems and so forth have non-instrumental value

(Jamieson 1997; Gardiner 2004; Moriarty, 2006; Hassoun and Wong forthcoming). Though it is not always clear whether these environmental ethicists think concern for one of these things always trumps concern for others. I

am pretty sure, for instance, that Gardiner thinks many things have non-instrumental value but it is not clear

whether they think concern for one of these things always trumps concern for others. Carafo is obviously

concerned about individuals and ecosystems and it is pretty clear that he does not think concern for human

interests always trumps concern for other parts of nature. Some deep ecologists probably also endorse an

inclusive environmental ethic (though those who commit to the Gaia hypothesis, for instance, may be better

classified as biocentrists) (Naess 2005). Even if, however, no one was an inclusive environmental ethicist this

article may be of interest. For, it at least illustrates some challenges for those who might be inclined to adopt the

position.

x This section draws heavily on (Hassoun 2009a).

xi This article talks about how humans, collectively, affect the natural world and about what climate change

policy humanity should embrace mainly to avoid worries about the non-identity problem and worries about responsibility for very small (e.g. individual) contributions to climate change. Note, however, that even the green house gasses individuals emit will probably impact some existing individuals, species, and ecosystems. For, it takes only a few years for $\mathrm{CO} 2$ emissions to affect the surface temperature of the ocean, for instance (Adams, 2009). 
xii Of course, environmental ethicists might also decide not to mitigate climate change but to help those negatively impacted by it in another way.

xiii As noted above, it may be impossible to harm or benefit future individuals and so forth but nothing here relies on that being possible. One need not even care if climate change brings about good and bad states of affairs for future individuals etc. For, climate change will harm and benefit some presently existing individuals etc.

xiv (Joyce \& Keigwin, 2003).

xv Again, to generate the problem we need not suppose that we can harm or benefit future individuals and so

forth. So, this article's argument need not contend with the non-identity problem.

xvi Similarly, (Sterba 1995) argues that species may benefit from the death of their weaker members.

xvii Allowing climate change to continue unabated is, after all, one such policy.

xviii Those who are only concerned about nature's interests or about rights violations might, for instance, argue that the non-identity problem gives one reason to reject this claim. For, we cannot benefit or harm these things by bringing them into existence or failing to do so. Nor do future species, ecosystems, and so forth have rights that can be violated in this way. (Rights-theorists might say, however, that we violate rights of currently non-existent individuals and so forth when we bring them into being very poorly off -- even when only alternative was to cause other beings to come into existence).

xix Taylor advances a series of priority principles but other biocentrists offer fewer or none at all. See, for

instance: (Schweitzer 1923; Sterba 1995; Taylor 1986). 
xx It might even be good, in some circumstances, to bring new species, ecosystems and so forth into existence.

Consider the choice between pushing two buttons. If you push the first button you will bring into existence a

lifeless planet. If you push the second, you will bring into existence a living planet with many individuals and

ecosystems. Most people would probably push the second button. Or consider a more realistic example. If a

degraded ecosystem cannot be restored, it might sometimes be good, to bring into existence some other

ecosystem in the area.

xxi Attempts to address climate change may bring greater harm to things that matter and, so, be unacceptable.

Even if mitigation is required, different mitigation strategies will impact different parts of nature in different

ways and, so, it is not clear which mitigation strategy is best.

xxii For discussion of different accounts of harm see: (Feinberg, 1984; Frankfurt, 1988; Hassoun, 2009c).

xxiii Presumably, some birds that fly into windmills would have existed even if we had not caused climate

change. If one objects to this example, however, it is possible to provide another.

xxiv For one of the most extensive ethics that attempts to address the problem of climate change see (Attfield

1999). Attfield does not, however, believe that ecosystems and species have non-instrumental value.

xxv I set aside here general worries about whether or not traditional versions of consequentialism can guide

action.

xxvi For discussion of consequentialism in environmental ethics and its incompleteness see: (Jamieson, 2003). 
xxvii Inclusive environmental ethicists are not the only one's that have this kind of problem. Many theories are incomplete and cannot tell us what to do about important challenges like climate change. Even some liberal theories that endorse more than one kind of freedom may face this sort of problem. Because they believe almost everything matters, however, the problem of incompleteness is particularly pressing for inclusive environmental ethicists.

xxviii Of course, there are similarly difficult and divisive empirical questions about how climate change will affect individuals, species, ecosystems, and the biosphere (IPCC, 2007 2007, 20). This article will focus primarily on figuring out what to do in the face of massive normative (as opposed to empirical) uncertainties. Some of the conclusions it will arrive at may, however, help in dealing with empirical uncertainties.

xxix I owe thanks to Jason Matteson for this point and to Ron Sandler for encouraging me to take very seriously the harms climate change may bring.

xxx Note that an inclusive environmental ethic might even fail to fulfill its author's desiderata for a good theory without being valueless.

xxxi Many of Schmidtz's examples show how it is possible to protect nature even without modifying property rights.

xxxii Of course, this article started from the observation that resolving these tensions requires some moral knowledge but, as the cases above illustrate, we often have the relevant knowledge. If all the things inclusive 
environmental ethicists care about matter then we know, for instance, that there is reason to protect both

individuals and ecosystems in Yellowstone.

xxxiii There are many methods for doing this. For discussion of some see: (Sit \& Taylor, 1998). Adaptive

management strategies might include some experimental and non-experimental research as well.

xxxiv Perhaps this section's arguments would be buttressed by a general commitment to some sort of

particularism on which we can have moral knowledge on the ground without a complete theory.

xxxv They might, for instance, succeed in deriving climate change policy from a complete and plausible theory

by focusing right now on doing more environmental ethics.

xxxvi This may apply to other large scale problems as well.

xxxvii This might be so if the initial permits are auctioned off to those with the greatest ability to pay. For, then,

the poorest will have to buy the permits they need for sustenance emissions.

xxxviii Perhaps because they have been around longer, many anthropocentric theories are also much more

developed (consider, for instance, John Rawls' theory of justice). They have to be extended, however, to account

for environmental values. On this also see: (Gardiner, 2009a; Gardiner, 2009b).

xxxix In the present case, we have seen how inclusive environmental ethicists might suggest that there are some

reasons for optimism. 